This PDF is a selection from a published volume from the National Bureau of Economic Research

Volume Title: Social Security Programs and Retirement Around the World: Disability Insurance Programs and Retirement

Volume Author/Editor: David A. Wise, editor

Volume Publisher: University of Chicago Press

Volume ISBNs: 0-226-26257-X, 978-0-226-26257-4 (cloth); 978-0-226-26260-4 (e-ISBN)

Volume URL: http://www.nber.org/books/wise14-1

Conference Date: September 26-28, 2013

Publication Date: January 2016

Chapter Title: Health Status, Disability, and Retirement Incentives in Belgium

Chapter Author(s): Alain Jousten, Mathieu Lefebvre, Sergio Perelman

Chapter URL: http://www.nber.org/chapters/c13324

Chapter pages in book: (p. $179-209)$ 


\title{
Health Status, Disability, and Retirement Incentives in Belgium
}

\author{
Alain Jousten, Mathieu Lefebvre, and Sergio Perelman
}

\subsection{Introduction}

In previous volumes of this NBER series on Social Security Programs and Retirement around the World, Pestieau and Stijns (1999), Dellis et al. (2004), Desmet et al. (2007), Jousten et al. (2010), and Jousten, Lefebvre, and Perelman (2012) documented how the Belgian social protection landscape offers a variety of pathways to retirement before reaching the normal retirement age (NRA) that is currently fixed at age sixty-five. For contractual wage earners, who represent the majority of the Belgian workforce, these early exit routes include an early exit option in the old-age pension scheme (OAP), conventional early retirement (CER), unemployment insurance (UI), and disability insurance (DI).

In this chapter, we focus our attention on the potential link between health status, disability insurance, and retirement for contractual wage earners ages fifty to sixty-four. Jousten, Lefebvre, and Perelman (2012) already explored the link between aggregate indicators of health and disability, on the one hand, and retirement on the other. The present study extends the analysis by taking a cross-sectional approach at the individual worker level.

Alain Jousten is professor of economics at the University of Liege, HEC Management School and Tax Institute, and a research fellow of the Institute for the Study of Labor (IZA) and of NETSPAR. Mathieu Lefebvre is assistant professor of economics at the University of Strasbourg. Sergio Perelman is honorary professor of economics, University of Liege, HEC Management School, and CREPP.

The authors acknowledge financial support from the SBO-project FLEMOSI (funded by IWT Flanders) and the Belspo project EMPOV (TA/00/45). We thank Lut Vanden Meersch (RIZIVINAMI) for giving us access to the data on DI participation and Ekaterina Tarantchenko for useful discussions and assistance. All remaining errors are our own. For acknowledgments, sources of research support, and disclosure of the authors' material financial relationships, if any, please see http://www.nber.org/chapters/c13324.ack. 
For this purpose we use the Belgian sample of SHARE, the Survey of Health, Ageing and Retirement in Europe, which has been collected since 2004. ${ }^{1}$ The survey is a cross-national panel database of microdata on health, socioeconomic status, and social and family networks of European individuals age fifty and older conducted since 2004-2005. It covers a broad range of variables of special interest for this study such as information on employment, health, and the household context. We use detailed self-reported information on health to compute a continuous health index and retrospective data to compute retirement incentives. We also construct an option value (OV) indicator as in Stock and Wise (1990) to compare the relative values of continued work versus retirement. We then use both of these indicators as independent variables in a microestimation of retirement decisions by means of a probit model.

While Dellis et al. (2004) relied on administrative records on Belgian workers, our estimation is based on SHARE survey data. One distinct advantage of SHARE is the availability of a rich set of health indicators (both subjective and objective); a distinct disadvantage is a significantly smaller availability of information on careers as compared to the pension register data.

This chapter is organized into several sections. The following section presents some stylized facts on disability participation among people age fifty to sixty-four. Our empirical approach is described in section 4.3, including a detailed description of the construction of a synthetic health index and the option value indicator. A rich set of probit models are estimated and results are reported in section 4.4. Section 4.5 provides microsimulations of some stylized reform scenarios. Section 4.6 concludes.

\subsection{The Role of Disability Insurance}

The role of DI has been changing quite substantially over time-as can be documented using administrative data. Jousten, Lefebvre, and Perelman (2012) provided a detailed discussion of the role of DI in the retirement landscape. Figures 4.1 and 4.2 summarize the trend in DI participation as

1. This paper uses data from SHARE wave 4, release 1.1.1, as of March 28, 2013, or SHARE waves 1 and 2, release 2.5.0, as of May 24, 2011, or SHARELIFE release 1, as of November 24, 2010. The SHARE data collection has been primarily funded by the European Commission through the 5th Framework Programme (project QLK6-CT2001-00360 in the thematic programme Quality of Life), through the 6th Framework Programme (projects SHARE-I3, RII-CT-2006-062193, COMPARE, CIT5-CT-2005-028857, and SHARELIFE, CIT4-CT-2006-028812) and through the 7th Framework Programme (SHARE-PREP, $\mathrm{N}^{\circ}$ 211909, SHARE-LEAP, $\mathrm{N}^{\circ} 227822$ and SHARE M4, $\mathrm{N}^{\circ} 261982$ ). Additional funding from the US National Institute on Aging (U01 AG09740-13S2, P01 AG005842, P01 AG08291, P30 AG12815, R21 AG025169, Y1-AG-4553-01, IAG BSR06-11 and OGHA 04-064) and the German Ministry of Education and Research as well as from various national sources is gratefully acknowledged (see www.share-project.org for a full list of funding institutions). 


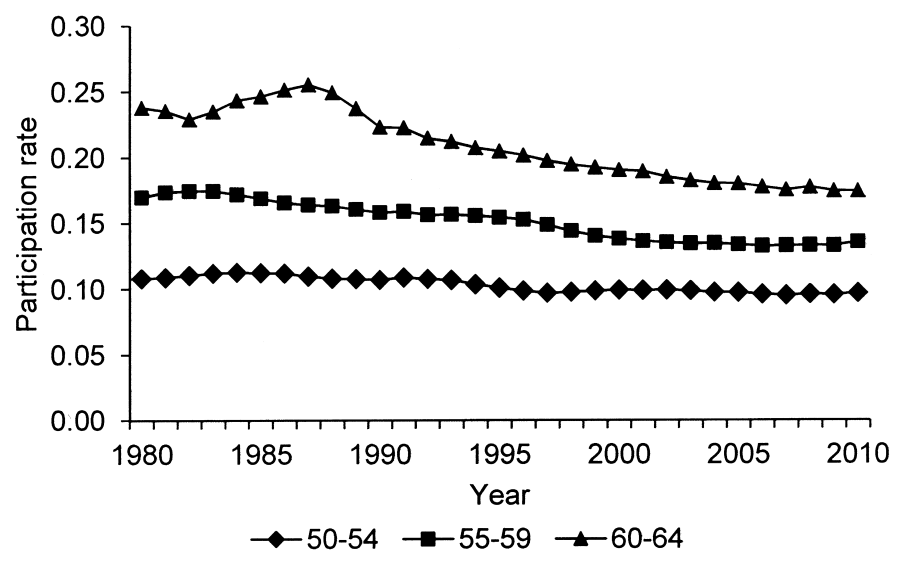

Fig. 4.1 The DI participation rate, men age fifty to sixty-four (1980-2010) Source: INAMI-RIZIV administrative records.

Note: The DI participation rates are obtained as percentage of beneficiaries as a share of the eligible wage-earner population in the age cohort.

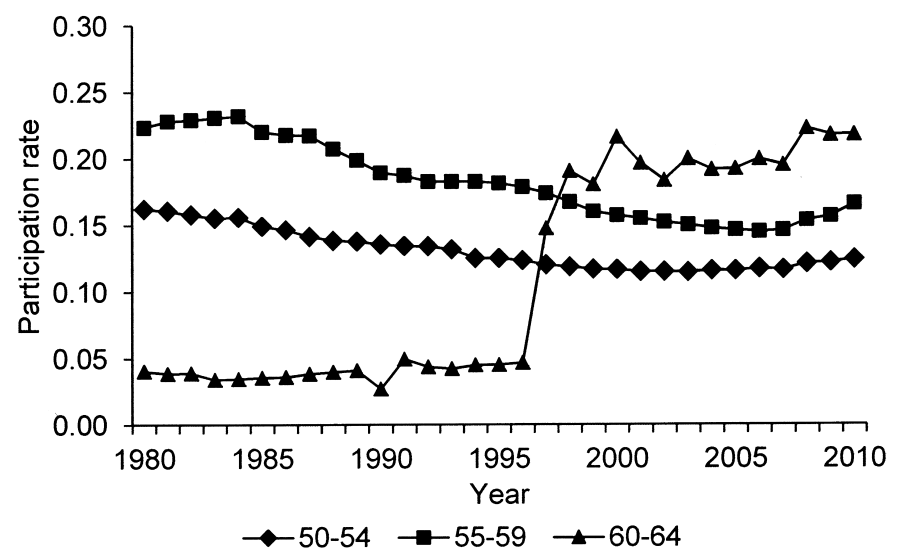

Fig. 4.2 The DI participation rate, women age fifty to sixty-four (1980-2010) Source: INAMI-RIZIV.

Note: The DI participation rates are obtained as percentage of beneficiaries as a share of the eligible wage-earner population in the age cohort.

observed in administrative data for the population of wage earners (age fifty and older), by age group and sex. ${ }^{2}$

For men, DI participation rates decreased over time for the three age cat-

2. The DI participation rate for a given age group is calculated using administrative records. The numerator is composed of the number of DI recipients who were awarded a DI benefit based on a work spell as a contractual wage earner. The denominator includes all active wage earners, as well as all social security beneficiaries (excluding pensioners) who are receiving benefits based on a work spell as a contractual wage earner. 


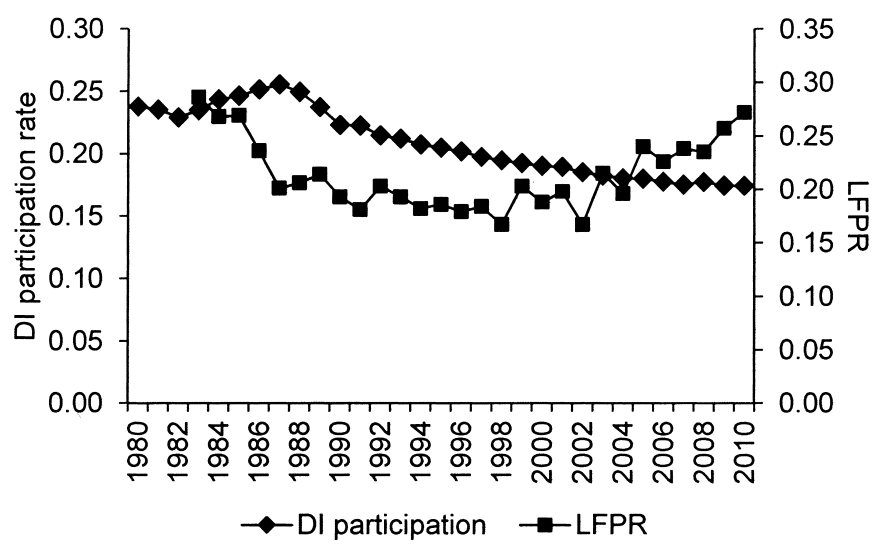

Fig. 4.3 The DI participation and labor force participation, men age sixty to sixtyfour (1980-2010)

Sources: INAMI-RIZIV and Eurostat.

Note: The DI participation rates are obtained as percentage of beneficiaries as a share of the eligible wage-earner population in the age cohort.

egories fifty to fifty-four, fifty-five to fifty-nine, and sixty to sixty-four, with a particularly strong decrease among the sixty to sixty-four category. As reported in Jousten, Lefebvre, and Perelman (2012), the decreasing evolution of DI cannot be traced to an increased DI stringency over time, but rather to the progressive introduction and successive decreases in stringency of other early exit routes. Among women, the longer-run trend toward a decrease in DI participation for the age groups fifty to fifty-four and fifty-five to fiftynine has more recently been reversed, with a likely link with stricter eligibility criteria in early retirement options as indicated by Jousten, Lefebvre, and Perelman (2012). Therefore, as in the case of men, the evolution is less in relation with changes in DI stringency than in relation with the evolution of eligibility rules under alternative pathways.

The situation for women ages sixty to sixty-four is an outlier to this picture, and predominantly driven by changes in the normal retirement age (NRA). Before 1997, the NRA was sixty years for women, de facto leading to very few active women beyond this age. From 1997 to 2009, women's normal age of retirement was progressively increased by one year of age every three calendar years so as to reach an NRA of sixty-five for women in 2009-the same as has been applicable for men for the last decades. ${ }^{3}$ This explains the fast increase in DI rates among women in this age category.

Figures 4.3 and 4.4 present the labor force participation rate and the DI

3. The alignment of the normal age of retirement for women to that of men was decided in response to two judgments of the European Court of Justice from 1993 ruling that differential criteria by sex constitute discrimination. 


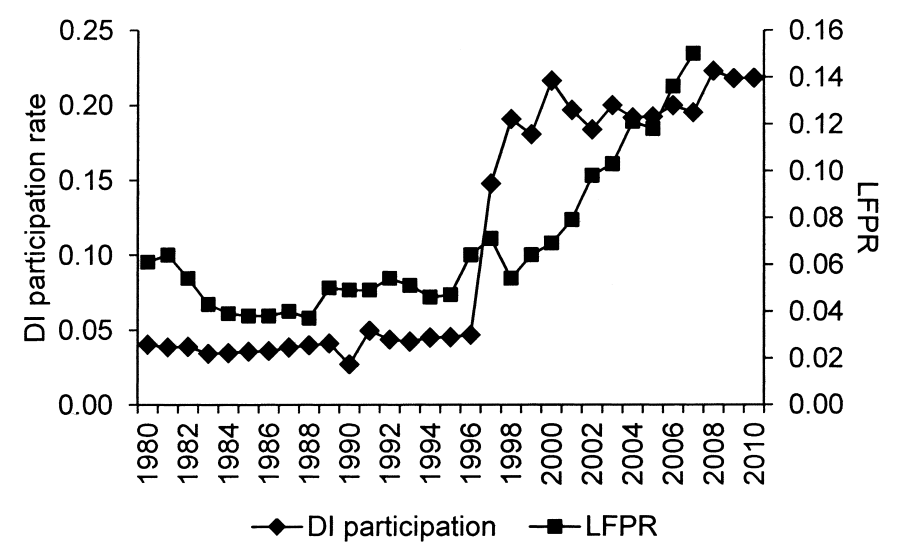

Fig. 4.4 The DI participation and labor force participation, women age sixty to sixty-four (1980-2010)

Sources: INAMI-RIZIV and Eurostat.

Note: The DI participation rates are obtained as percentage of eligible wage-earner population in the same age cohort.

participation rate for the older age group of sixty to sixty-four. While the DI participation for women follows the labor force participation for the reason explained above, it is not the case for men, where trends are opposite in the later part of the observation period. This apparent lack of synchronization between the variables can be traced to several causes, two of which are particularly marked. First, multiple early retirement pathways exist and interact, hence leading to a weakening of the link between each one of them and the aggregate labor market outcomes. Second, since the late 1990s a reversal of the longstanding trend toward lower effective retirement could be observed all across a wide variety of countries (see the previous volumes of this series), and this to a large degree irrespective of the incentive structure prevailing in any specific country.

Disability insurance has a very diverse impact on the various subgroups of the population - particularly when comparing along the education and health dimensions. As Belgium does not have any systematically collected administrative data on those topics, we turn to SHARE to derive some stylized facts. Figures 4.5 and 4.6 illustrate the evolution over the period ranging from the first wave of SHARE (2004-2005) to the last one available to date (2010-2011). ${ }^{4}$ They summarize the DI probabilities for male and female wage earners, respectively, within the fifty to sixty-four age group stratified by education level. Overall, there is a strong negative gradient between edu-

4. Three waves of SHARE are useable for this analysis: waves 1 (2004-2005), 2 (2006-2007), and 4 (2010-2011). Wave 3 conducted in 2008-2009 (known as SHARELIFE) does not include questions on individuals' current situation, but mainly retrospective questions. 


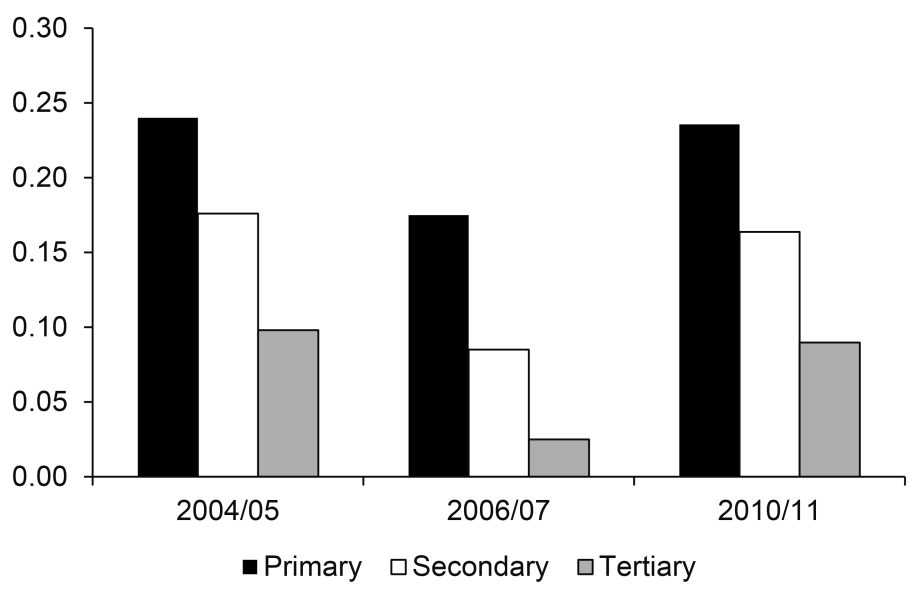

Fig. 4.5 The DI probability by education, male wage earners age fifty to sixty-four Source: Authors' calculation based on SHARE data (waves 1,2, and 4).

Note: The DI probability is obtained as the number of individuals receiving DI benefits in the wage-earner population (active or unemployed).

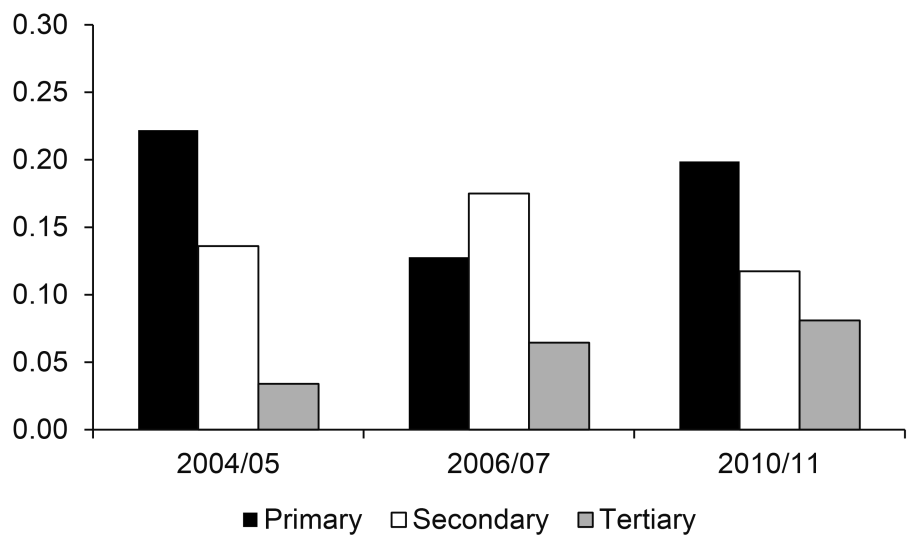

Fig. 4.6 The DI probability by education, female wage earners age fifty to sixty-four

Source: Authors' calculation based on SHARE data (waves 1, 2, and 4).

Note: The DI probability is obtained as the number of individuals receiving DI benefits in the wage-earner population (active or unemployed).

cation level and DI probability for wage earners. The sole exception is the case of women in 2006-2007 (SHARE wave 2), where the DI probability is higher for the intermediate category than for the less educated, likely due to a small-sample problem.

Figures 4.7 and 4.8 illustrate the evolution of DI probabilities among men and women, respectively, by health quintiles. Without entering in the details 


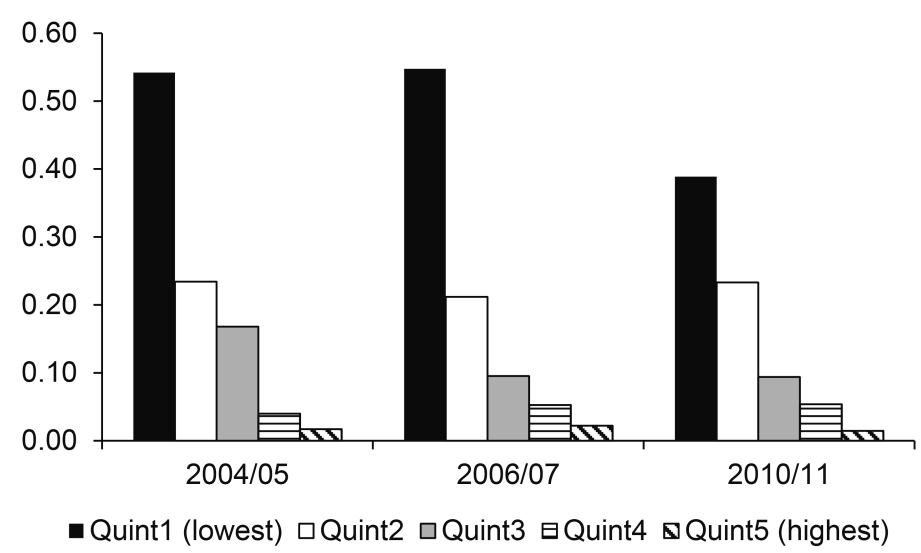

Fig. 4.7 The DI probability by health quintiles, male wage earners age fifty to sixty-four

Source: Authors' calculation based on SHARE data (waves 1, 2, and 4).

Note: The DI probability is obtained as the number of individuals receiving DI benefits in the total population.

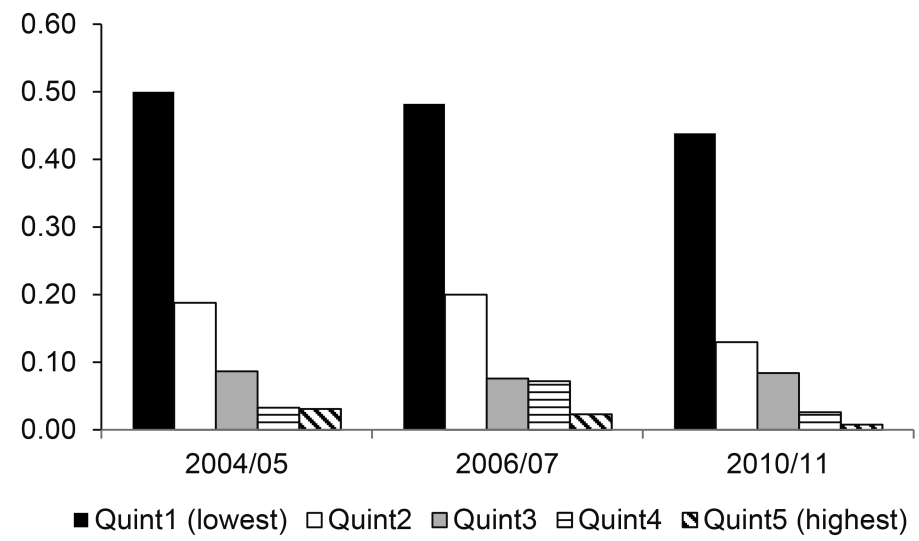

Fig. 4.8 The DI probability by health quintiles, female wage earners age fifty to sixty-four

Source: Authors' calculation based on SHARE data (waves 1, 2, and 4).

Note: The DI probability is obtained as the number of individuals receiving DI benefits in the total population.

of health quintiles computations, which will be presented in detail in section 4.4.3, we observe in these figures that DI probabilities are positively related to health in SHARE, but above all that for people in the lower health quintile the DI probability reaches values as high as 50 percent in some survey waves.

Figures 4.9 and 4.10 combine the two factors of health and education and display the DI probability when crossing these two variables. We observe, in 


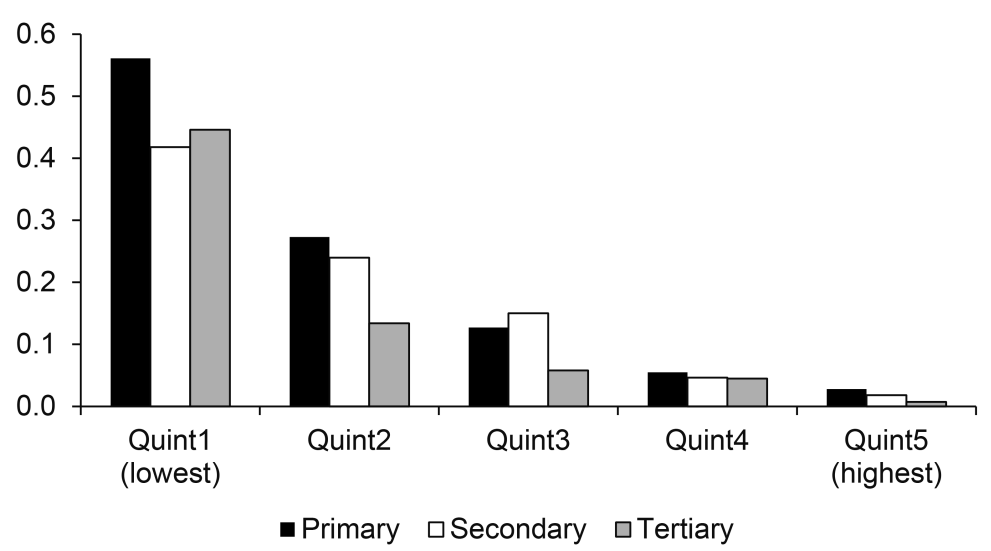

Fig. 4.9 The DI probability by health quintiles and education, male wage earners age fifty to sixty-four

Source: Authors' calculation based on SHARE data (waves 1, 2, and 4).

Note: The DI probability is obtained as the number of individuals receiving DI benefits in the total population.

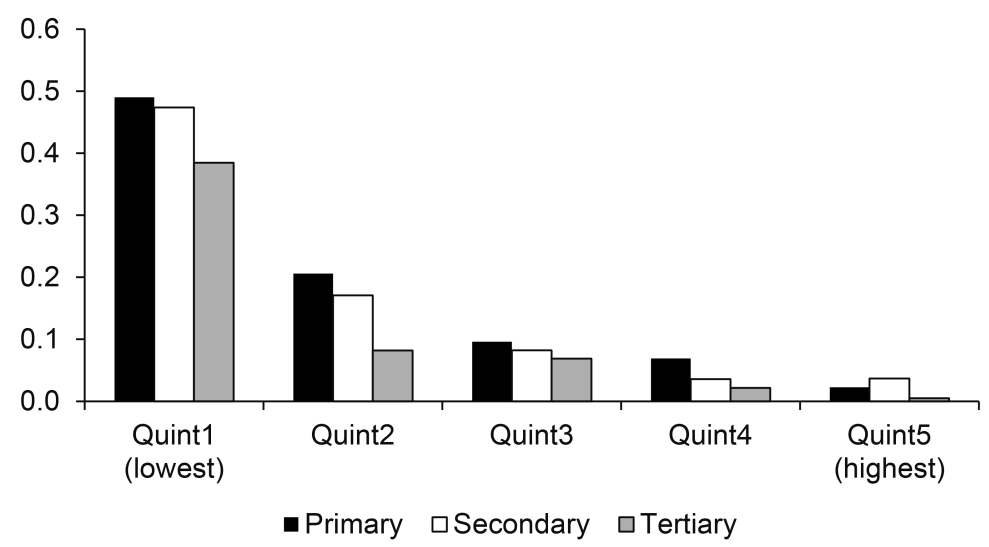

Fig. 4.10 The DI probability by health quintiles and education, female wage earners age fifty to sixty-four

Source: Authors' calculation based on SHARE data (waves 1, 2, and 4).

Note: The DI probability is obtained as the number of individuals receiving DI benefits in the total population.

addition to the effect of health on DI probability, a more mixed pattern of education within each health quintile.

Finally, table 4.1 shows the employment rate of individuals age fifty to sixty-four as computed based on the combined SHARE waves 1, 2, and 4. Employment increases along the health gradient, both for men and women, and is positively correlated with education. 
Table 4.1

Employment rate at age fifty-five to sixty-four by health and education

\begin{tabular}{|c|c|c|c|c|c|}
\hline & Primary & Secondary & Tertiary & & \\
\hline \multicolumn{6}{|c|}{ By education level } \\
\hline Men & 0.419 & 0.555 & 0.657 & & \\
\hline \multirow[t]{2}{*}{ Women } & 0.312 & 0.424 & 0.594 & & \\
\hline & Quint 1 (lowest) & Quint 2 & Quint 3 & Quint 4 & Quint 5 (highest) \\
\hline \multicolumn{6}{|c|}{ By health quintile } \\
\hline Men & 0.248 & 0.434 & 0.580 & 0.640 & 0.675 \\
\hline Women & 0.147 & 0.346 & 0.418 & 0.526 & 0.512 \\
\hline
\end{tabular}

Source: Authors' calculation based on SHARE data (waves 1, 2, and 4).

\subsection{Empirical Approach}

As mentioned before, our main goal is to understand the influence of health status and the provisions of social protection schemes on retirement decisions. For this purpose we estimate a discrete-time retirement model in which exit from the labor market $\left(R_{i}=1\right)$ is explained by social protection incentives, health, and other covariates.

For individual $i$ :

$$
\operatorname{Pr}\left[R_{i}=1\right]=\operatorname{Pr}\left[X_{i}^{\prime} \beta+\delta \mathrm{OV}_{i}+\gamma H_{i}\right],
$$

where $X_{i}^{\prime}$ is a vector of independent variables, $\mathrm{OV}_{i}$ is a social security incentive, an option value measure, and $H_{i}$ is a measure of health status.

In our econometric analysis, we use the first two waves of data from SHARE collected in 2004-2005 and 2006-2007 for Belgium. The third wave of data, known as SHARELIFE (collected in 2008-2009), asked all previous respondents (waves 1 and 2) and their partners to provide information not on their current situation, but on their entire life histories. This provides retrospective information on childhood, health, living, and professional career. We combine the first two waves with the retrospective data from SHARELIFE to obtain a full career history for each individual. ${ }^{5}$ For individuals surveyed in any wave we can observe when they exited the labor market and through which pathways. This means that while there are usually two years between each wave, we can observe year-to-year transitions. The advantage is that instead of seeing an individual just once between two waves, we follow him along the years between two waves and we know his actual status in each year. We restrict the sample to the individuals who are between ages fifty and sixty-four. In each wave (1 or 2) we select those

5. The SHARE wave 4 data was also available but not usable for this purpose given that wave 3, SHARELIFE, did not report detailed information on health and on other key variables for this study. 
individuals who were employed as wage earners and exclude retired, unemployed, sick, and disabled. We also exclude individuals for whom retrospective information is not available in SHARELIFE. Finally, we drop all the records for the years that are subsequent to the year when the individual exited the labor force. Our analytical sample consists of 1,210 observations.

Two crucial steps in our analysis relate to the derivation of a synthetic health measure and the calculation of a summary indicator of retirement incentives. For the former, we rely on a continuous health index computed using a principal component analysis based on nearly twenty-five selfreported health indicators. For the latter, we rely on an "inclusive" version of the concept of option value, de facto a weighted average of the option values for each pathway to retirement. We detail the approach below.

\subsubsection{Measurement of Health Status}

Identifying the effects of health on retirement is complicated because people's health is not directly observable. The use of surveys wherein people report subjective self-assessments of their physical capacity can often be misleading. Indeed, it is a subjective assessment and there is no reason to expect that such assessments are entirely comparable across individuals. Also, answers may not be independent of the outcomes we wish to study. For example, individuals who are inactive often have an incentive to report worse than actual health. In such situations, subjective health indicators measure leisure preferences rather than true health status.

It is thus preferable to use objective indicators of health. The issue is to find objective measures that are correlated with work capacity and that truly reflect the individual's ability to work. The SHARE data contain a variety of objective and subjective measures of health. Using objective measures of physical ability in addition to self-reported health status, we propose to derive a latent health index similar to Poterba, Venti, and Wise (2010). To construct the index we use responses to twenty-four questions and obtain the first principal component of these underlying indicators of health. The first principal component is the weighted average of the health indicators, where the weights are chosen to maximize the proportion of the variance of the indicators that can be explained by the first principal component. ${ }^{6}$

All data from waves 1,2, and 4 of SHARE are used to calculate the principal components, with ages ranging from 50 to 101 . These are then in a second step applied to all observations of waves 1 and 2 that are the basis for our econometric analysis - de facto attributing a health index for each individual in each one of the two waves under study. Thus an individual may experience changes of the health status across the survey waves. The health score obtained from the first principal component is converted into

6. The list of health questions used in the principal component analysis is available in appendix table 4A.1, as well as the correlation coefficients corresponding to the first component. 


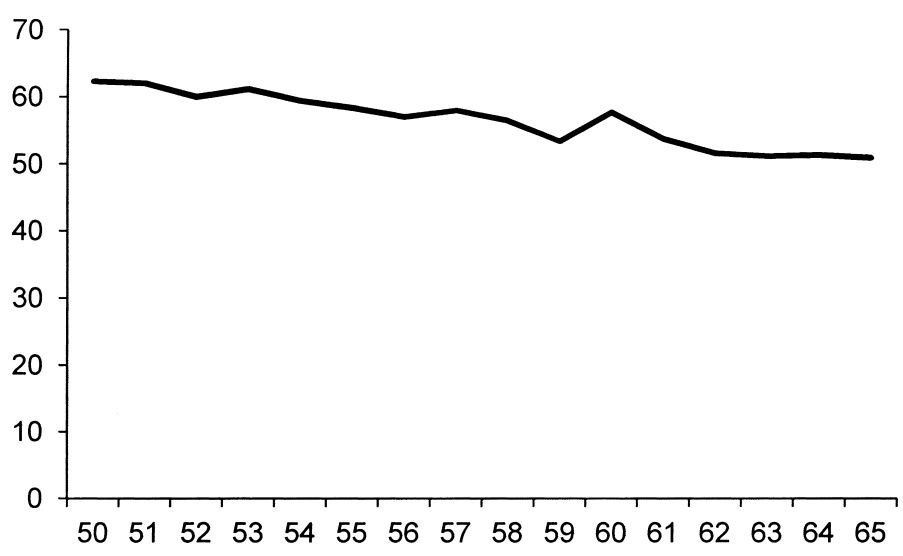

Fig. 4.11 Average health percentile by age

Source: Authors' calculation based on a two-step procedure. First, the underlying principal components are calculated based on twenty-four health questions drawn from SHARE waves 1,2 , and 4 for the age range 50-101. Second, these estimates are then applied to individuals of waves 1 and 2 in the age range fifty to sixty-five.

percentile scores for each observation with 1 the worst health and 100 the best. Later on in the analysis we group persons by health status quintiles using this score. Figure 4.11 displays the average health percentile in Belgium by age for individuals age fifty to sixty-five. We observe in this figure that, as expected, the health indicator decreases with age, with a blip at age sixty. Further, it is perfectly plausible for the average health percentile to remain above the 50 percent markup until the statutory retirement age - with progressively lower levels observed above that age.

\subsubsection{Pathways to Retirement}

Wage earners face several typical pathways to retirement. A first pathway consists of an immediate transfer from work into the old-age pension system (OAP). The OAP currently allows claiming early retirement as of age sixty, when some career requirements are met. The normal retirement age, at which anybody can claim OAP benefits independently of career requirements, is currently set at age sixty-five for both men and women. Notice that during the first two waves of SHARE data collection from 2004 to 2005 the normal retirement age for women was still under the transitory regime, reaching sixty-three for the first wave and sixty-four for the second.

Benefits correspond to 75 percent of average lifetime earnings for oneearner couples and to 60 percent for singles - with two-earner couples having the right to a top-up to the said 75 percent if the secondary earner's pension is smaller than this household supplement. Claiming early does not imply any actuarial adjustment of benefits as compared to claiming at NRA.

A full career corresponds to forty-five years of earnings or assimilated 
periods, with average lifetime earnings computed over the same forty-fiveyear period. A specificity of the Belgian retirement landscape is that periods spent on replacement income (such as CER, UI, or DI) fully count as years worked in the computation of the retirement benefits. For any such periods, fictive wages are inserted into the earnings history. For the period of our analysis, these fictive wages correspond to the real wage that the individual was earning right before his period of inactivity. Benefits are shielded against inflation through an automatic price adjustment, and an earning test frequently applies before the NRA.

Next to the public pension system, several early retirement pathways have emerged. The CER program was explicitly designed as an early exit route. It is based on collective agreements, which are negotiated between employee and employer associations. Within this program, the workers exit the labor market and receive an unemployment compensation paid by the UI system and a bonus paid by the employer, which equals half of the difference between the individual's last net wage and the special unemployment benefit applicable to CER beneficiaries. Both benefits and reference wage have caps and floors. The CER program implies that workers cannot draw public pension benefits before the NRA, at which age he is automatically rolled over into the OAP system. The generally applicable eligibility rule sets out that they have to satisfy a minimum age of fifty-eight and a career of at least twenty-five years, but exceptions exist that allow some workers to exit through CER as early as age fifty with as little as a career of ten years.

Regular UI benefits represent a second effective exit route into retirement. In Belgium there is no generally applicable time limit for UI benefit receipt, except for the automatic rollover provision of the unemployed into retirement upon reaching the NRA. The level of these benefits depends on the family status and the duration of the unemployment spell. In theory, they are equal to 60 percent of the previous net wage if the individual is single or has family dependents. If the spouse or partner has income, benefits are equal to 55 percent of last net wage. In practice, they have caps and floors that vary according to the duration of the unemployment spell, de facto somewhat weakening the mechanical nature of the mentioned replacement rates.

Within the group of unemployed, special rules are applicable to some categories of older workers, a system known as old-age unemployment (OAU) as documented in Jousten, Lefebvre, and Perelman (2012). While the system has played an important role in the Belgian retirement landscape, we do not explicitly take it into account in our analysis for two reasons. First, in SHARE data, OAU is observationally indistinguishable from UI. Second, successive policy changes over the course of the last decade have effectively dismantled the system as a stand-alone program and brought it back into the realm of the regular UI. In fact, the two key benefits of the system as compared to regular UI have been decoupled and significantly tightened: 


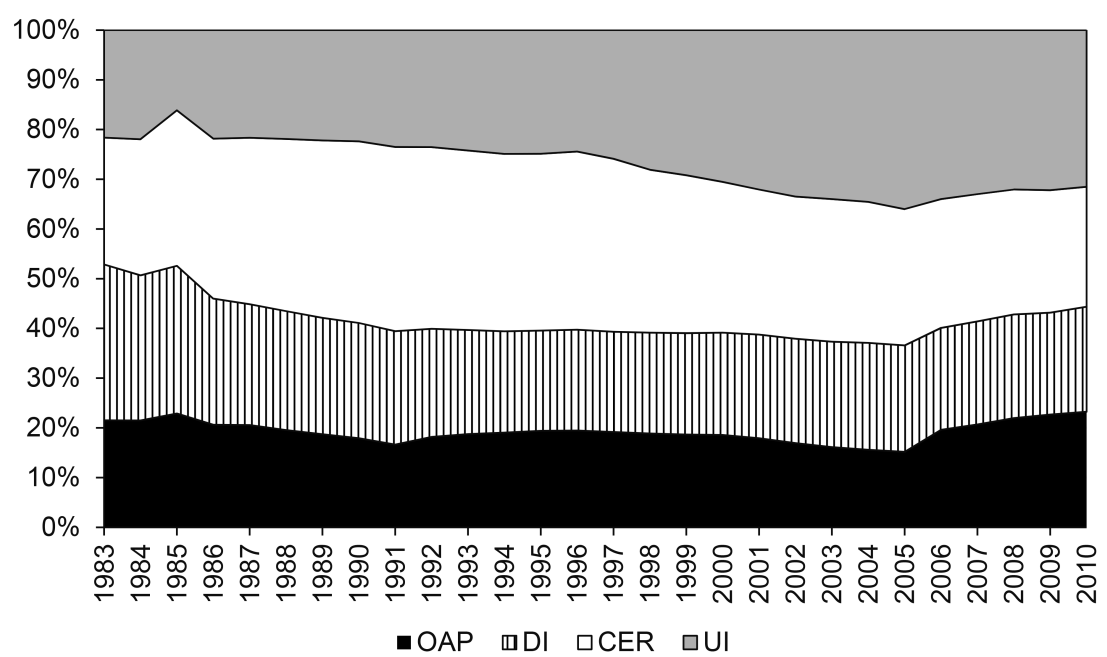

Fig. 4.12 Pathways to retirement-male wage earners, age fifty to sixty-four (\%) Sources: INAMI, ONEM, ONP, and Belgostat.

Note: The denominator is the number of individuals in the same age group who were covered under the wage-earner regime and are currently inactive. The numerator is the split of these people across the various social security programs in the age group fifty to sixty-four.

a waiver from the general job search requirement and the conditions for benefiting from a seniority supplement.

Last but not least, though a priori exclusively targeted at those withdrawing from the labor market for reasons of bad health, DI may also serve as an early exit route. The eligibility is based on loss of earnings capacity. In order to be eligible, the worker has to suffer from a loss of earnings capacity of 66 percent over a period of twelve months. The benefit level is a function of the household status and is equal to 65 percent of reference wage if the worker has dependents. It is reduced to 53 percent if the insured lives alone and to 45 percent if the individual cohabits. As for unemployment, benefits are payable up to the NRA with automatic rollover into OAP occurring at that age.

Figures 4.12 and 4.13 provide empirical evidence on the importance of the various programs across time for men and women, separately. The percentages are computed as the proportion of all social protection beneficiaries, within the fifty- to sixty-four-years-old category, in a particular program at each year. We see the role of the various pathways in absorbing the change in one or another-with UI effectively playing the role of program of last resort.

For men we observe over the last years an increase in the proportion of pensioners (OAP). For women, figure 4.13, we observe on the contrary a dramatic decrease in the proportion of pensioners, due to the progressive 


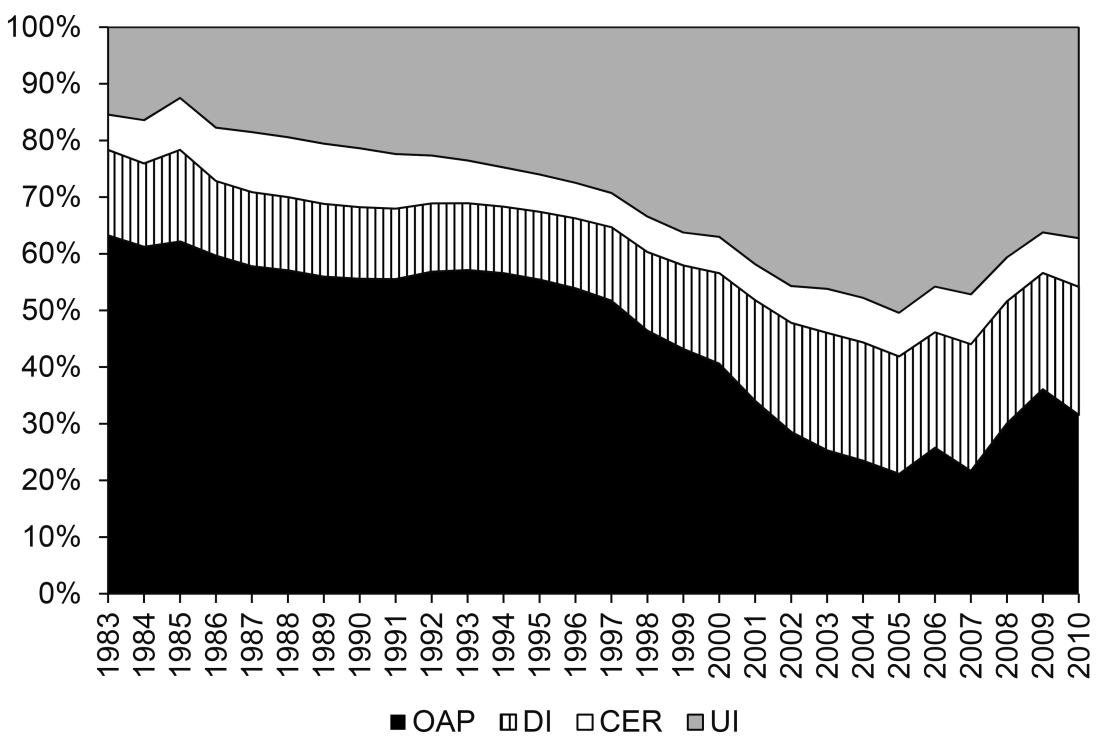

Fig. 4.13 Pathways to retirement-female wage earners, age fifty to sixty-four ( $\%)$ Sources: INAMI, ONEM, ONP, and Belgostat.

Note: The denominator is the number of individuals in the same age group who were covered under the wage-earner regime and are currently inactive. The numerator is the split of these people across the various social security programs in the age group fifty to sixty-four.

postponement of the NRA from sixty to sixty-five compensated mainly by unemployment (UI) and, in a lower proportion, by disability (DI). Over the transition period, from 1997 to 2009 , the number of women age fifty- to sixty-four years old and beneficiaries of these programs increase more than 50 percent.

\subsubsection{Weighting the Pathways to Retirement}

As described above, there are four potential pathways to retirement for wage earners in Belgium. Our empirical strategy relies on the computation of a financial indicator that summarizes the incentives associated with the four pathways. The idea is to calculate for each of these pathways to retirement an incentive measure that is aggregated into one final inclusive measure using path-specific weights.

Since we cannot observe each individual's exact eligibility for the various exit routes, we are not able to determine the probability that a given pathway is a realistic option for the individual. Instead we impute to each pathway a weight that is, on average, a realistic prospect for the population age fifty and older. The weights are based on administrative data. We use the share of the population for the age group fifty to sixty-four that is either on disability (DI), unemployment (UI), or early retirement (CER). Old-age 


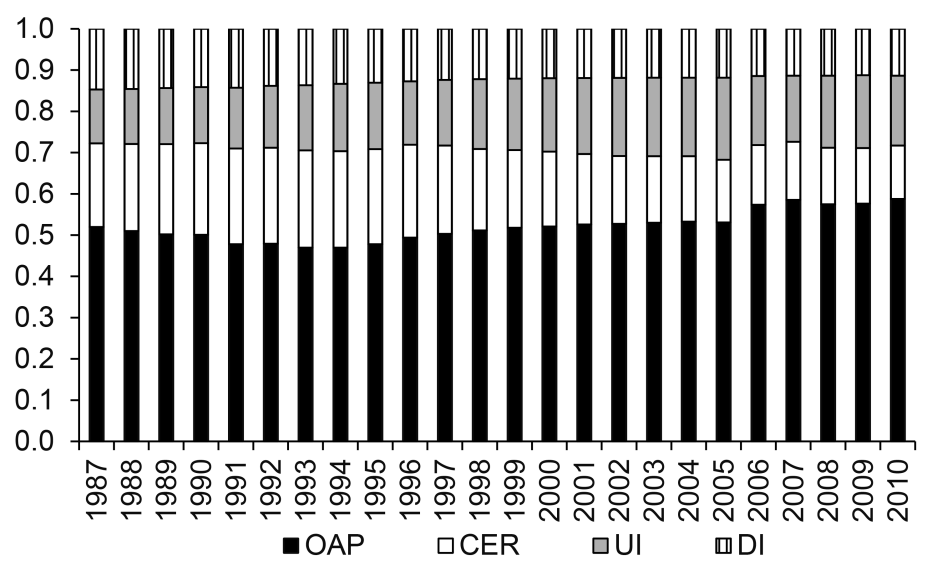

Fig. 4.14 Pathway weights by year-male wage earners, age fifty to sixty-four Sources: INAMI, ONEM, and Belgostat.

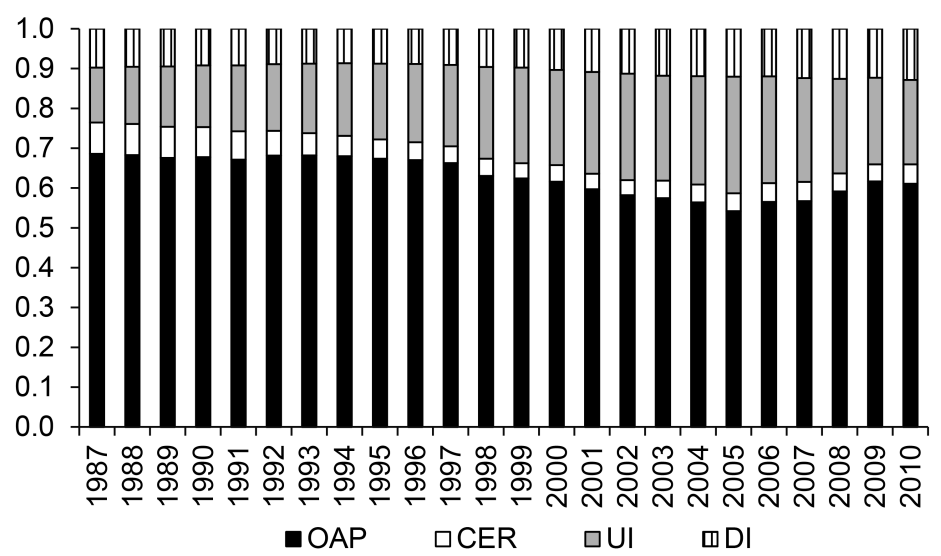

Fig. 4.15 Pathway weights by year-female wage earners, age fifty to sixty-four Sources: INAMI, ONEM, and Belgostat.

pension (OAP) takes the residual such that the sum of the weights is equal to one. The fifty to sixty-four age window corresponds to the main ages at risk of retirement in Belgium. Figures 4.14 and 4.15 present these weights for the last twenty years. Interestingly, we observe for men a decrease of the weight of disability but an increase for women due to the postponement of women's normal age of retirement.

\subsubsection{Option Value Calculations}

Thanks to the data from SHARELIFE we are able to reconstruct the individual's career history and thus, ultimately, to calculate the entitlements 
to benefits. The SHARELIFE survey asks the respondents to provide start and end dates of each paid job they had, the characteristics of the job, as well as the first monthly wage. For those who are still employed at the time of the interview, the last monthly wage is also asked. All these amounts are after taxes.

This information is used to construct a panel with one wage observation per year for each individual, from the first job until the interview year. For simplicity we convert all amounts to 2008 euro dollars. The wage path is obtained using linear interpolation of wages for the years where we lack wage information. During unemployment, sickness, and disability as well as early retirement periods, fictive wages equal to the last observed wage are assigned, as required by calculation rules of public pension. As a result, we can project each individual's entitlements under the four exit routes based on each individual's own earnings history.

As indicated before, our financial incentive measure (OV) is a forwardlooking measure based on the concept of option value of retirement, as defined by Stock and Wise (1990). In the option value model, an individual evaluates the expected present discounted value of income for all possible future retirement ages through a route to retirement and then compares the value of retirement today versus the value at the optimal age. It is based on a utility-maximization framework. Under the reduced form formulation, the value at age $a$ of retirement $h, V_{a}(h)$, is given by (to simplify the presentation, we hide here the individual's subscript index $i$ ):

$$
V_{a}(h)=\sum_{s=a}^{h-1} \theta(s) \rho^{s-a} W_{s}^{\gamma}+\sum_{s=h}^{\infty} \theta(s) \rho^{s-a}\left[k B_{h}(s)\right]^{\gamma}
$$

where $\theta(s)$ is the survival probability at age $s, \rho$ is the rate of time preference, and $B_{h}(s)$ is the benefit expected at age $s$ if the worker retires at age $h ; W_{s}$ is the earnings from continued working. Depending on the household situation, $\theta(s)$ also accounts for survivor benefits. ${ }^{7}$

The variable $\gamma$ is a parameter of relative risk aversion and is set equal to 0.75 . Finally, the parameter $k$ expresses the relative weight of utility of retirement income and is set equal to 1.5 .

Letting $h^{*}$ be the year in the future at which the individual maximizes her/his expected value of retiring, the option value (OV) is then defined as the difference in utility terms between retiring at the best point in the future $\left(h^{*}\right)$ or now $(a)$ :

$$
\mathrm{OV}_{a}\left(h^{*}\right)=V_{a}\left(h^{*}\right)-V_{a}(a)
$$

We rely on an inclusive version of the option value that is a weighted average of the option value associated to each potential route (pathway)

7. We use a discount rate of 3 percent, which is very often used in the literature. Mortality tables by sex for the Belgian population are used to compute $\theta(\mathrm{s})$. The source is the Human Mortality Database (www.mortality.org). 


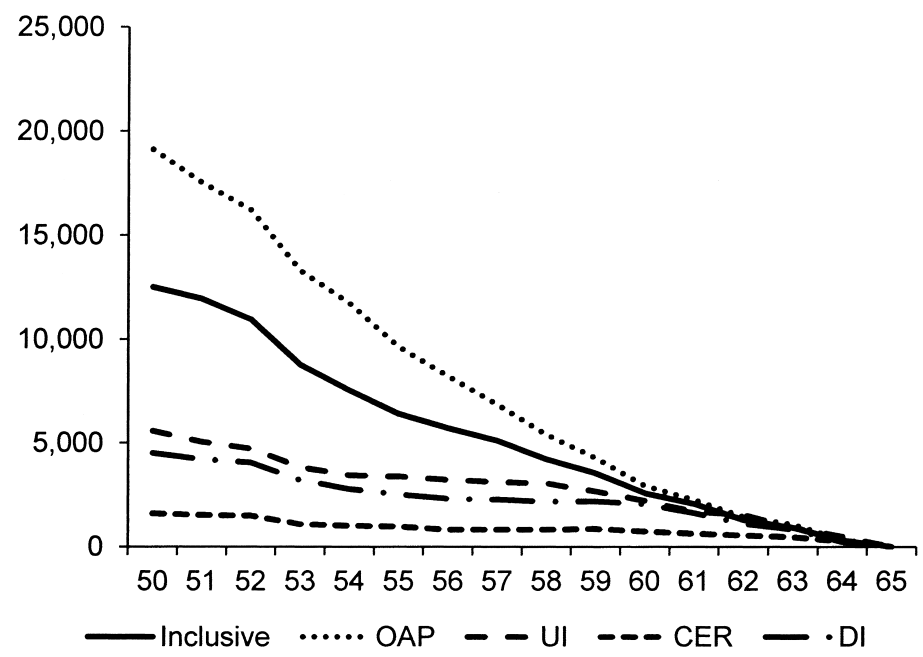

Fig. 4.16 Mean OV by age - male wage earners

Source: Authors' calculations based on SHARE data.

Note: The lines correspond to a cohort of fifty-year-olds that we follow as it ages.

to retirement. In order to compute the OV for each pathway to retirement, we need to make a projection of individual-level wages. In our analysis, we assume a real growth of wages of 0 going forward. Using this information and the whole career information compiled from SHARELIFE, we compute expected benefit flows for every pathway to retirement (DI, UI, CER, and OAP) for each possible age of retirement up to the NRA. Finally, we integrate expected benefits and expected wages in equations (2) and (3) to derive the option value for each retirement pathway.

Figures 4.16 and 4.17 show the mean OV for each pathway for men and women. The pattern is downward sloping for each OV as well as for both men and women. That is, that the utility to be gained from working one more year tends to decline with age and gets closer to zero at the NRA. The positive nature of the $\mathrm{OV}$ over the whole age range is mainly due to the utility term associated with wage income and the benefit formulae applicable under the various Belgian social security programs. Figures 4.16 and 4.17 show that the incentive to stay in the labor force when having an option to exit through CER, UI, and DI is rather weak at ages below sixty, as the OV indicator is flat over the entire age range. It is only when focusing on the OAP route that retirement before sixty is a highly uninteresting option - as for the latter case, the individual would be getting zero income until the age of sixty (the early retirement age of the OAP system).

The inclusive OV indicator summarizes these path-specific OV's into a single measure using the previously derived weights. For each individual and for each possible age of retirement, inclusive OV is calculated. The mean of the inclusive OV by age is plotted in figures 4.16 and 4.17 by means of a 


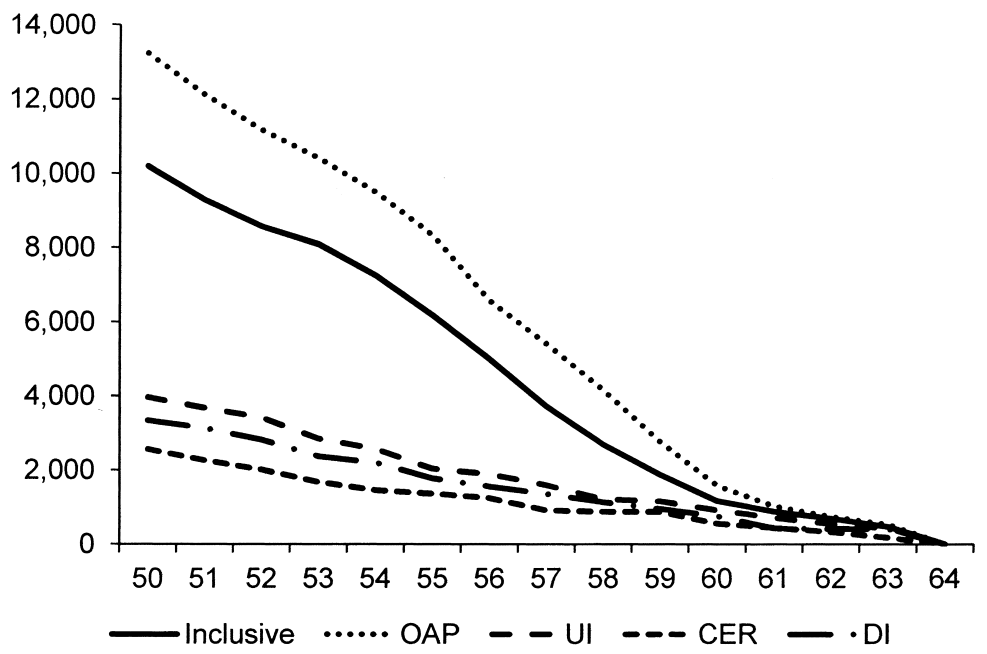

Fig. 4.17 Mean OV by age-female wage earners

Source: Authors' calculations based on SHARE data.

Note: The lines correspond to a cohort of fifty-year-olds that we follow as it ages.

continuous curve, for men and women, respectively. Unsurprisingly, given the weight structure, the OV associated with OAP exerts a predominant effect on the inclusive $\mathrm{OV}$ indicator, hence leading to an overall incentive to delay retirement.

\subsection{Results}

In this section we present a series of results obtained from binary probit estimations. The dependent variable is the binary retirement indicator: it is equal to one if the individual exits the labor force within the year, and zero otherwise. In each specification, we include the inclusive OV as a summary measure of financial incentive, to which we add a series of control variables that vary depending on the specification. Marginal effects are presented.

In specifications (1) and (2) in table 4.2, we only include the inclusive $\mathrm{OV}$ as well as a health indicator in the specification. For heath, we use dummies for each health quintile (based on the previously defined health index). Specification (1) uses linear age, while specification (2) is set up with age dummies. In specifications (3) and (4), we include a richer set of sociodemographic variables such as gender, the level of education, as well as dummies for marital status and active spouses. Furthermore, to capture wealth effects, we include the total household financial assets.

Specification (5) conceptually deviates from the previous ones in that it does not contain any linear or age dummy effect. The rationale for this alternative is related to an identification problem in all of these regressions: 


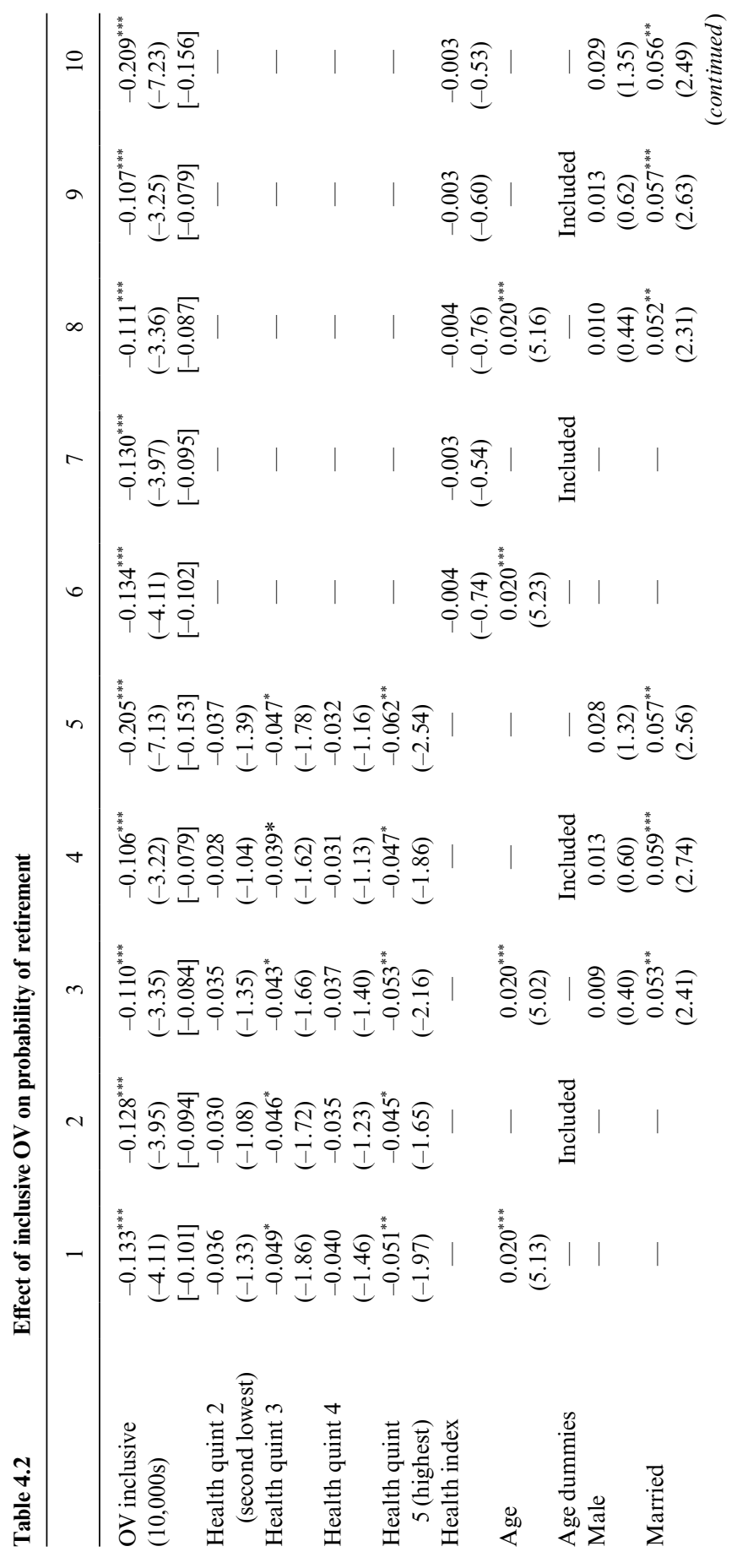




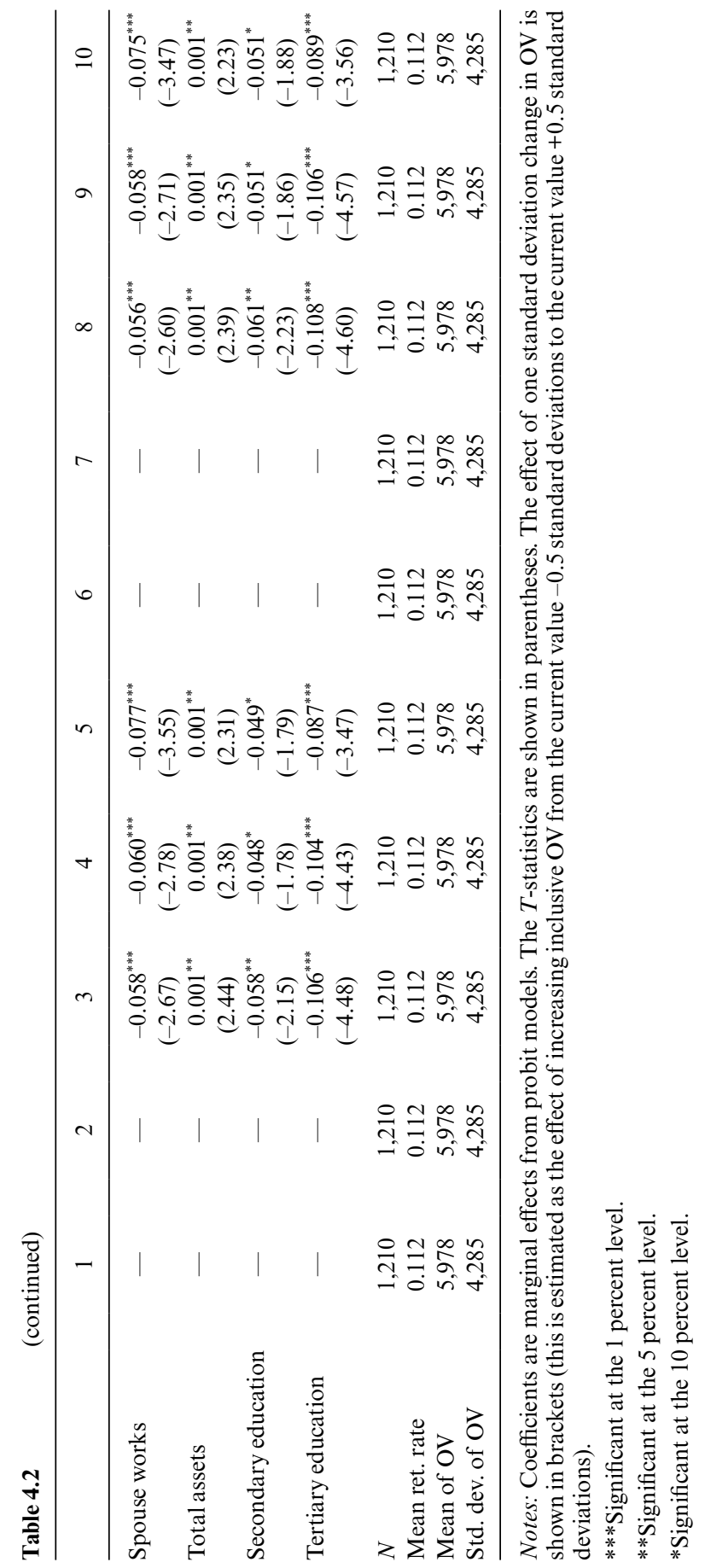


Which is the pure effect of age on retirement, independent of the effect of pension schemes rules? The data we use does not allow us to address this identification issue, many more waves of SHARE would be necessary. Hence, in specifications (1) to (4), the age dummies or the linear age trend capture a mix of both.

In specification (5) we take an extreme alternative by estimating the effect of OV under the assumption that any age-of-eligibility effect is fully taken into account by the inclusive $\mathrm{OV}$ variable. Implicitly, this also implies that we give the inclusive $\mathrm{OV}$ incentive variable a maximum role, though it does not by itself address the identification problem - it just takes a slightly different view. The approach turns out to be particularly useful when trying to gauge the effect of reform simulations (see the next section).

Finally, specifications (6) to (10) are similar to the five first specifications except that it includes a different indicator for the health status of individuals. In this second batch of specifications, health is introduced as the linear health index obtained from the principal component analysis rather than the relative position in the population by quintile.

The incentive measure turns out to be strongly significant in all specifications. The effect is negative, as expected, which means that a larger value of continued work leads to lower probability of retirement. In brackets, we also report the effect of a one standard deviation change in the $\mathrm{OV}$ as the coefficient on the OV can be sensitive to the mean and the variance of the OV. The results are similar to those for the coefficient on OV. In line with expectations, specifications (5) and (10) show a much bigger effect of the inclusive $\mathrm{OV}$ as it now captures the full scope of incentives that are otherwise partially captured by the age term.

Regarding health, results are somewhat unexpected. Individuals in the fifth quintile are significantly less likely to retire (at thresholds of 5 or 10 percent, according to the specification) than individuals in the first quintile. Only for some specifications and for a 10 percent significance level, individuals of the third quintile also display similar features. When looking at specifications with the health index, no significant pattern can be distinguished as a function of the health index. This even holds true when interacting the incentive measure with the health index as in table 4.3.

Our findings with regard to the influence of health status have clear policy relevance: they show that the link between health and retirement in Belgium is either weak or not significant. This stands in sharp contrast to the analysis of section 4.2, indicating the importance of performing econometric analysis instead of relying on mere correlations.

While the gender dummy is insignificant, other variables have strong impacts: age plays a significant role. Education also has a strong explanatory power, with higher education leading to significantly lower retirement probabilities. Being married has a positive impact on the likelihood of retirement, while having an active spouse reduces the retirement probability. Household 
Table 4.3

Effect of inclusive OV with health index interaction

\begin{tabular}{lcccc}
\hline & 1 & 2 & 3 & 4 \\
\hline OV & $-0.135^{* * *}$ & $-0.131^{* * *}$ & $-0.113^{* * *}$ & $-0.109^{* * *}$ \\
& $(-4.17)$ & $(-4.02)$ & $(-3.44)$ & $(-3.32)$ \\
Health*OV & {$[-0.058]$} & {$[-0.054]$} & {$[-0.048]$} & {$[-0.046]$} \\
& -0.017 & -0.016 & -0.018 & -0.017 \\
Health index & $(-1.05)$ & $(-0.99)$ & $(-1.17)$ & $(-1.14)$ \\
& 0.003 & 0.004 & 0.003 & 0.004 \\
Linear age & $(0.33)$ & $(0.41)$ & $(0.36)$ & $(0.45)$ \\
Age dummies & $\mathrm{X}$ & & $\mathrm{X}$ & \\
Other Xs & & $\mathrm{X}$ & & $\mathrm{X}$ \\
$N$ & 1,210 & 1,210 & 1,210 & $\mathrm{X}$ \\
Mean ret. rate & 0.112 & 0.112 & 0.112 & 0.112 \\
Mean of OV & 5,978 & 5,978 & 5,978 & 5,978 \\
Std. dev. of OV & 4,285 & 4,285 & 4,285 & 4,285 \\
\hline
\end{tabular}

Notes: Models are the same as models 5-8 in table 4.2, with the addition of an OV*health index interaction. Coefficients are marginal effects from probit models. The $T$-statistics are shown in parentheses. The effect of one standard deviation change in OV is shown in brackets (this is estimated as the effect of increasing inclusive $\mathrm{OV}$ from the current value -0.5 standard deviations to the current value +0.5 standard deviations).

***Significant at the 1 percent level.

**Significant at the 5 percent level.

*Significant at the 10 percent level.

financial wealth also leads to a higher probability of retirement - in line with intuition.

Table 4.4 is analogous to specifications (1) to (4) of table 4.2 but instead of the inclusive $\mathrm{OV}$, we use the percent gain in the utility from delaying retirement till the optimal retirement date. The underlying idea is simple: a similar level of OV can represent very different realities for different individuals, as they may have very different starting positions in terms of initial incomes and well-being. Hence, we define this percent gain in the utility of delayed retirement as the ratio of OV to the level of utility the individual would obtain if he were to immediately retire. ${ }^{8}$

The estimated coefficients on the incentive variable again turn out highly significant and robust to the specification choice. The observed effect of the financial incentive variable is much stronger than in table 4.2 , indicating that the relation to initial levels of well-being matter in the Belgian retirement landscape. ${ }^{9}$

8. In terms of the terminology of the previous section, this corresponds to dividing expression (3) by expression (2), the latter evaluated upon immediate retirement.

9. We have tested alternative specifications including the two terms of this ratio as separate variables and have not found any stable relation. Results can be obtained from the authors upon request. 
Table 4.4 Effect of percentage gain in inclusive $\mathrm{OV}$ on probability of retirement

\begin{tabular}{|c|c|c|c|c|}
\hline & 1 & 2 & 3 & 4 \\
\hline OV change & $\begin{array}{l}-0.389^{* * *} \\
(-4.63)\end{array}$ & $\begin{array}{l}-0.388^{* * *} \\
(-4.59)\end{array}$ & $\begin{array}{l}-0.320^{* * *} \\
(-3.91)\end{array}$ & $\begin{array}{l}-0.313^{* * *} \\
(-3.82)\end{array}$ \\
\hline Linear age & $\mathrm{X}$ & & $\mathrm{X}$ & \\
\hline Age dummies & & $\mathrm{X}$ & & $\mathrm{X}$ \\
\hline Health quintiles & $\mathrm{X}$ & $\mathrm{X}$ & $\mathrm{X}$ & $\mathrm{X}$ \\
\hline Other Xs & & & $\mathrm{X}$ & $\mathrm{X}$ \\
\hline$N$ & 1,210 & 1,210 & 1,210 & 1,210 \\
\hline Mean ret. rate & 0.112 & 0.112 & 0.112 & 0.112 \\
\hline Mean of $\%$ OV & 0.252 & 0.252 & 0.252 & 0.252 \\
\hline Std. dev. of $\% \mathrm{OV}$ & 0.169 & 0.169 & 0.169 & 0.169 \\
\hline
\end{tabular}

Notes: Models are the same as models $1-4$ in table 4.2. Coefficients are marginal effects from probit models. The $T$-statistics are shown in parentheses.

$* * *$ Significant at the 1 percent level.

**Significant at the 5 percent level.

*Significant at the 10 percent level.

\subsection{Implication of the Results}

\subsubsection{Fit of the Model}

Figures 4.18 and 4.19 compare by age, for men and women separately, the predicted retirement probabilities to the actual probabilities. The predicted probabilities are obtained from the full specification with health quintiles and age dummies (specification [4] in table 4.2). It will be our baseline for the simulations hereafter. The predictions follow closely the change in the actual probabilities, both for men and women. Although not reported here, the predictions made on the basis of estimations with a linear age are not so good. This indicates that the age dummies are important to capture some of the nonlinearities that the incentives or the health cannot capture, such as the key role played by eligibility ages.

Figures 4.20 and 4.21 display the simulated labor market survival process for men and women, separately. These figures are derived using the crosssectional actual and predicted retirement probabilities of the preceding figures to simulate the survival for a hypothetical cohort of fifty-year-olds to whom we apply these cross-sectional retirement probabilities as they age. Implicitly, this assumes that the currently observed age patterns of retirement remain valid for the hypothetical cohort going forward to the future. ${ }^{10}$

Figure 4.22 relates the effective retirement behavior to what could be expected from our OV measures. It plots the cumulative retirement probabilities and the cumulative percentage of individuals who, according to our

10. This calculation ignores the effect of mortality. 


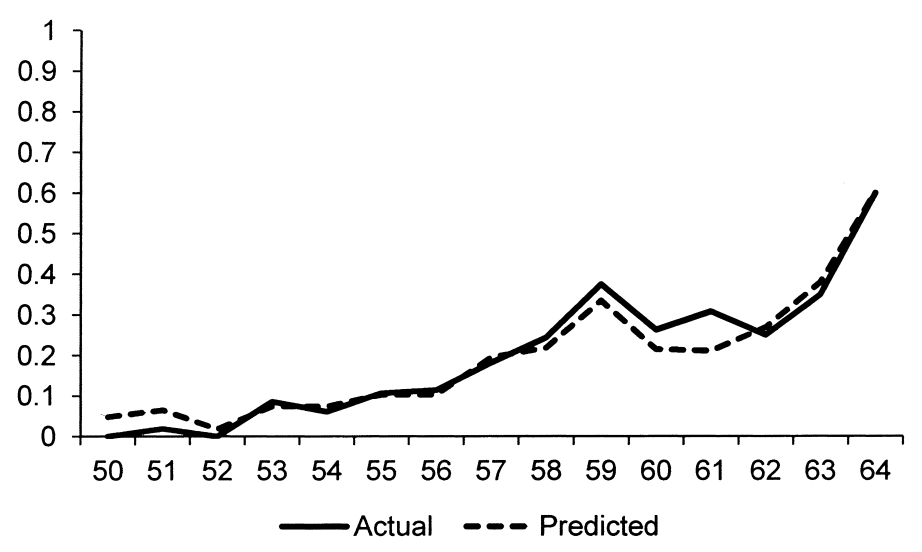

Fig. 4.18 Actual versus predicted retirement probabilities, male wage earners Source: Authors' calculation based on SHARE data.

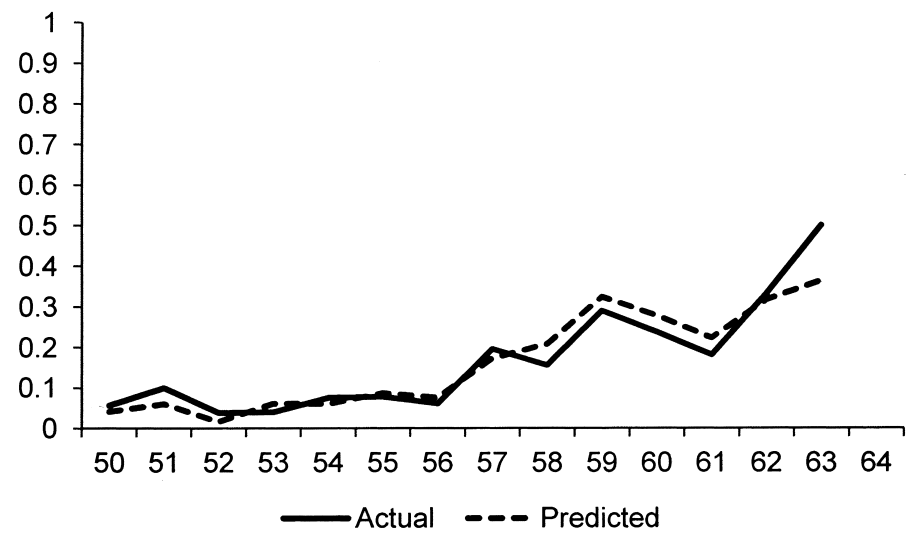

Fig. 4.19 Actual versus predicted retirement probabilities, female wage earners Source: Authors' calculation based on SHARE data.

Note: The SHARE sample does not include any female wage earners working beyond the age of sixty-three.

incentive measures, have reached the maximum utility. It shows that a large majority of wage earners in Belgium retire before they have reached the utility maximizing age of retirement as predicted by the model.

\subsubsection{Simulations}

Using our estimations results of section 4.4, we investigate the effect of a change in the Belgian retirement architecture on retirement behavior. We use specification (4) of table 4.2 as our reference.

The first type of simulation (simulation [1]) considers that all persons in 


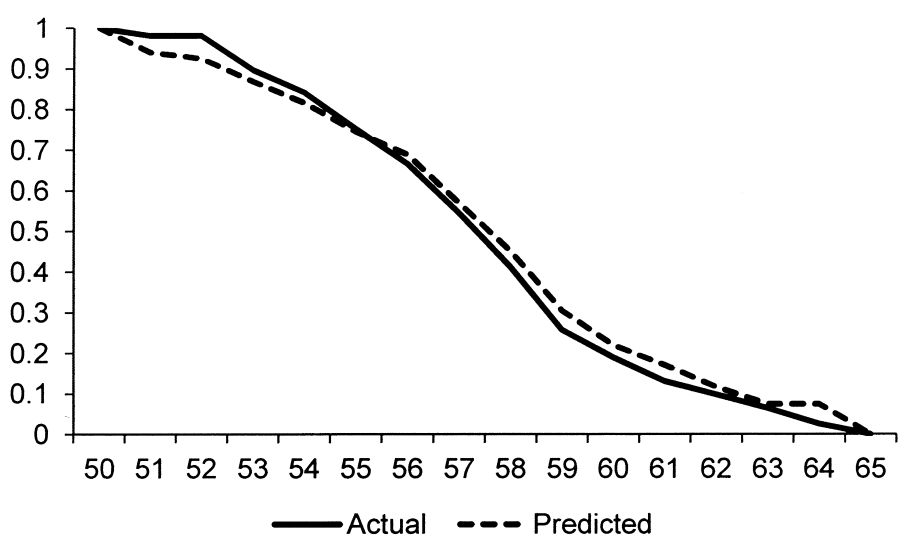

Fig. 4.20 Simulated labor market survival probabilities, male wage earners Source: Authors' calculation based on SHARE data.

Note: The curves represent simulated labor market survival probabilities for a cohort of fiftyyear-olds, to whom we apply the cross-sectional retirement probabilities of figure 4.18.

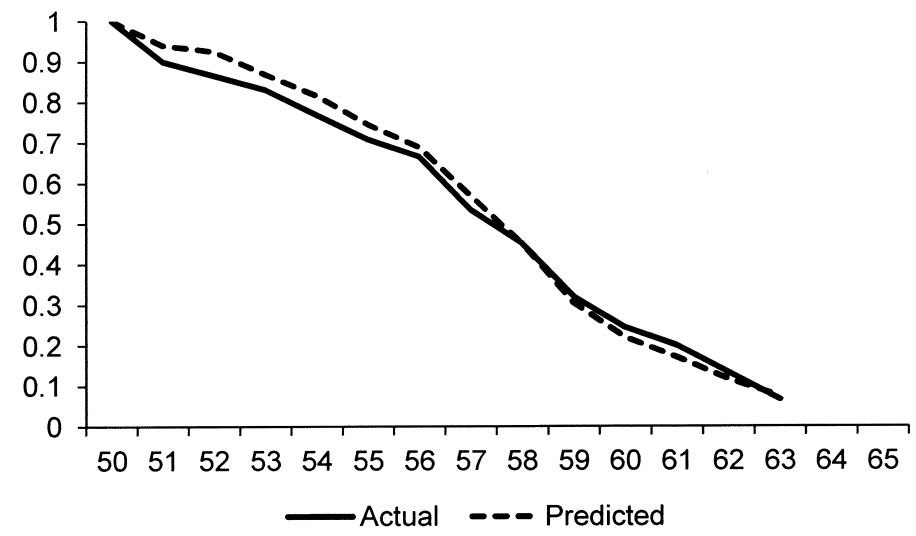

Fig. 4.21 Simulated actual versus predicted labor market survival probabilities, women

Source: Authors' calculation based on SHARE data.

Note: The curves represent simulated labor market survival probabilities for a cohort of fiftyyear-olds, to whom we apply the cross-sectional retirement probabilities of figure 4.19. No account is taken of actual mortality.

the sample face only one of the four exit routes rather than a weighted combination of all. Expressed differently, we simulate the impact on retirement behavior of restricting access - and thus OVs - to one of the programs: OAP, CER, UI, or DI. We apply the estimated coefficients of the inclusive OV to these path-specific OVs. Implicitly, we thus view our estimates from the previous section as being instrumented estimates of the true relations- 


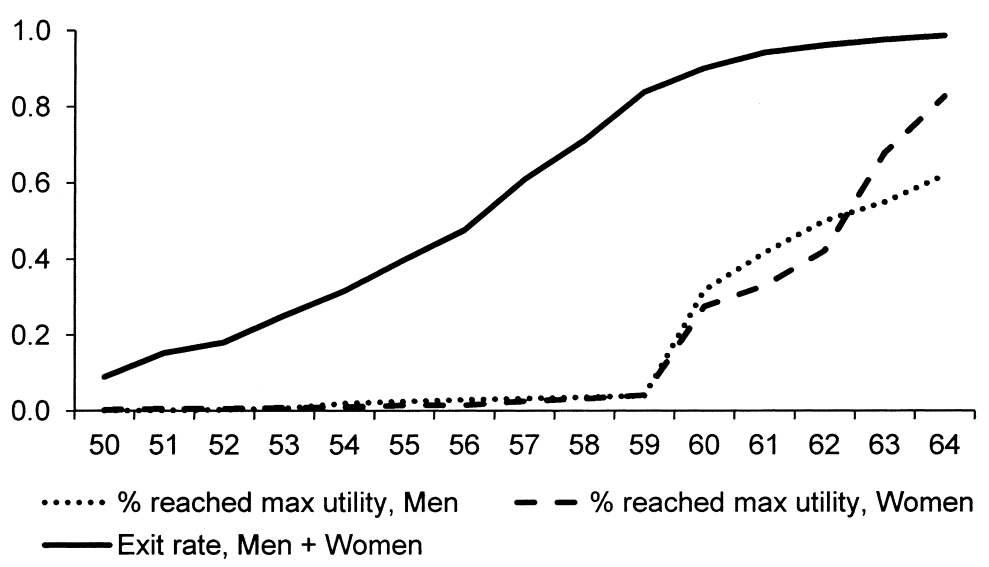

Fig. 4.22 Share of wage earners having reached maximum utility and cumulative retirement probability by age

Source: Authors' calculation based on SHARE data.

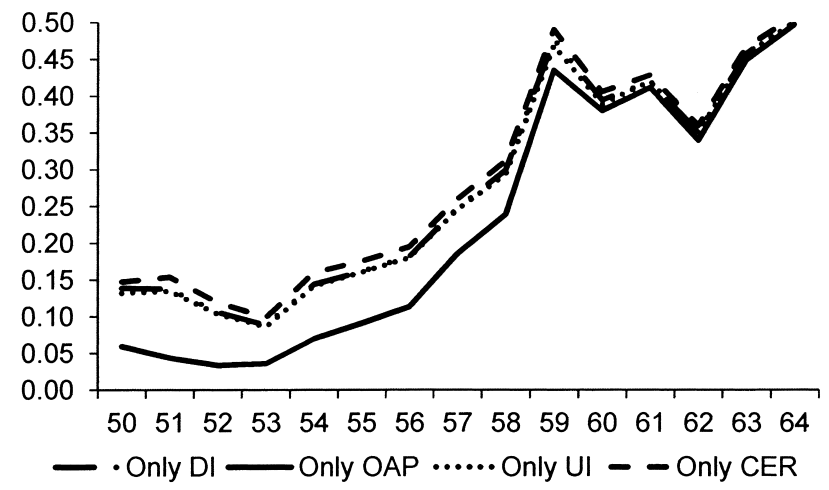

Fig. 4.23 Retirement probabilities by pathway

Source: Authors' calculation based on SHARE data.

with the population-wide averages serving as instruments for true individual eligibility. Figure 4.23 summarizes the results in terms of retirement hazards by age under the alternative scenarios. In line with figures 4.16 and 4.17, the strongest differences appear between the OAP and the other pathways with OAP leading to substantially lower hazard rates. Restricting access to CER, UI, or DI would lead to only marginally different retirement patterns. Figure 4.24 provides another look at the same underlying information. As for figures 4.20 and 4.21, it again represents the simulated labor market survival for a hypothetical cohort of fifty-year-olds facing the same retirement hazards in the future as the cross-sectional data reveals at present. Table 4.5 provides a simple summary statistic based on the same information as figure 


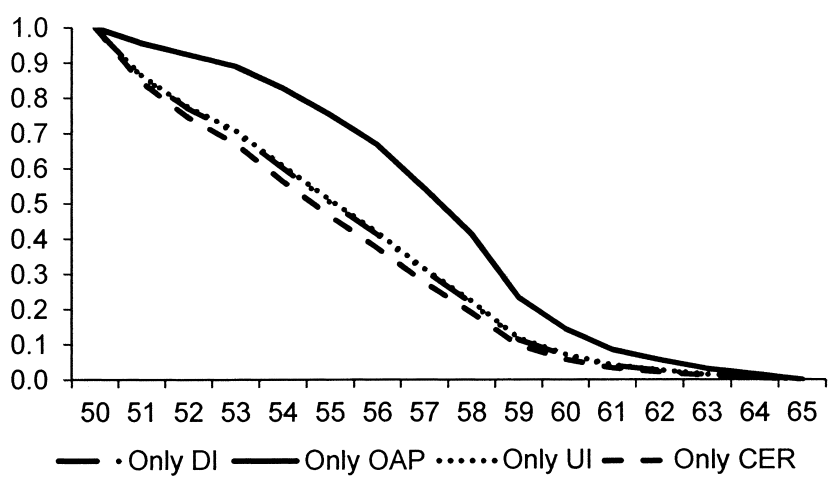

Fig. 4.24 Survival probabilities by pathway

Source: Authors' calculation based on SHARE data.

Note: The curves represent simulated labor market survival probabilities for a cohort of fiftyyear-olds, to whom we apple the cross-sectional retirement probabilities of figure 4.23. No account is taken of actual mortality.

4.24: the expected remaining years of work after age fifty. It shows that the average expected remaining working life differs by more than two years, or expressed in relative terms by approximately 40 percent between the most generous pathway (CER) and the least generous pathway (OAP), with UI and DI falling in between.

A second type of simulation (simulation [2]) focuses exclusively on reforms that affect the people who are observed to be exiting through the DI pathway. The idea is simple: if we restrict the availability of DI, it will most directly affect those currently on the beneficiary rolls. Hence, the second type of simulation explores how this specific subgroup would react to changes in the program generosity that it faces. A priori, one could expect this population to be less responsive to financial incentives if the system actually (partially or completely) achieves its goal of covering people with a loss of earnings ability. The results are again summarized in table 4.5. Overall, DI recipients are significantly less responsive to changes in their incentives than the overall population. This would point to significant differences in their characteristics as compared to the population at large. Also, these simulations show that the differences between DI, CER, and UI are sufficiently marginal so as not to have any noticeable effect in terms of average retirement age.

In a third set of simulations (simulation [3]), we still focus on those who retired through DI, but this time with a less categorical policy implementation. In order to mimic the effect of a tightening of the eligibility criteria, we randomly assign a fraction of them (one-third or two-thirds) to the DI path and the remainder is excluded from DI. To reflect the communicating vessels idea, we successively explore the assignment of these people who are refused DI to the various programs. Allocating them to CER or UI means 


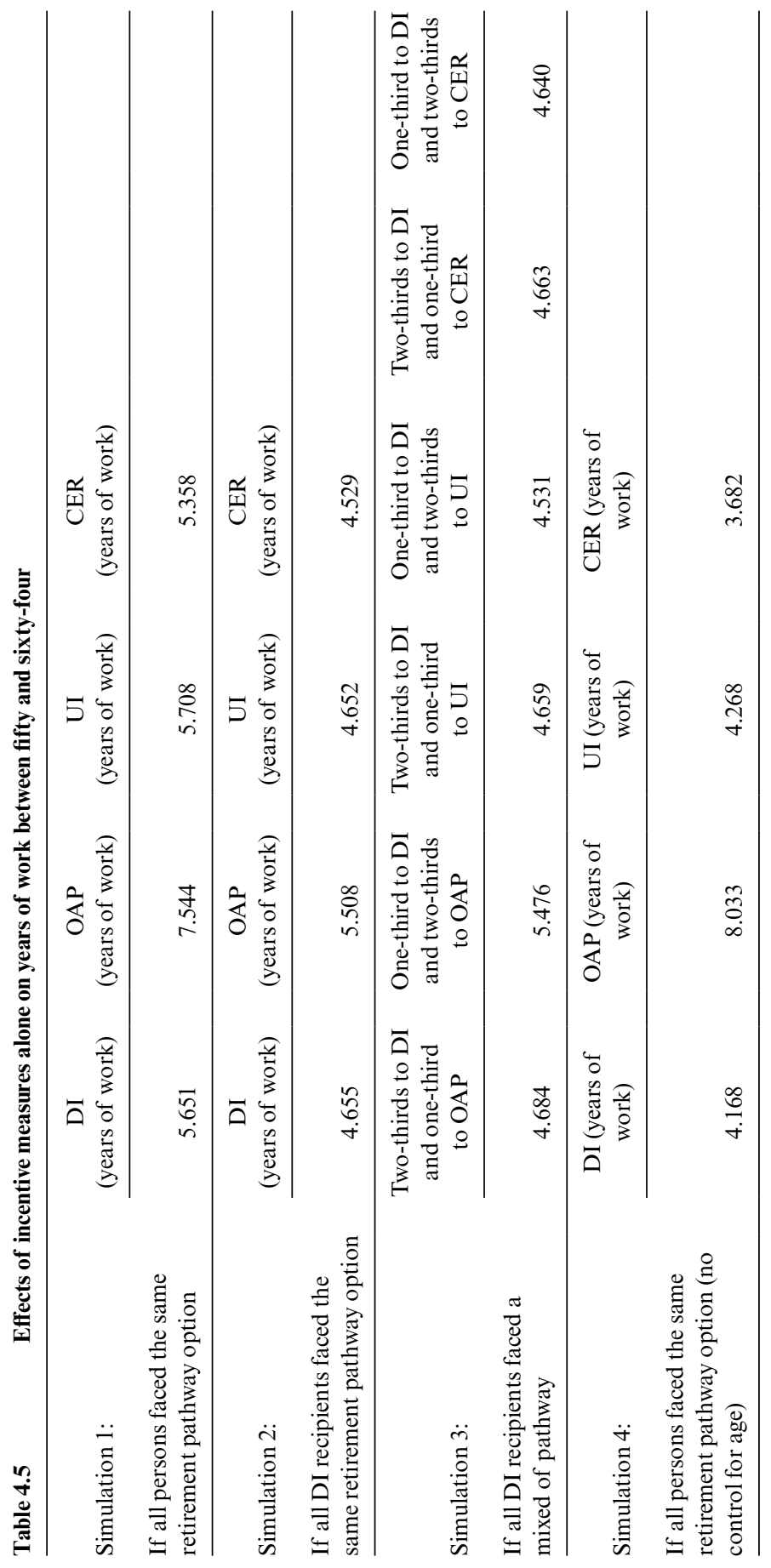


that access to these programs is not tightly monitored, hence leading to a shift between social security programs. Allocating them to OAP can be seen as a residual approach, whereby these individuals would be kept at bay from the UI and DI programs, de facto depriving them of current income until the early retirement age under OAP rules.

Simulations (2) and (3) illustrate that differences between CER, UI, and DI are sufficiently small so as to lead to absolutely marginal effects when shifting people between these programs. There is an immediate policy relevance of this finding: when limiting access to DI without strictly enforcing access conditions for UI and CER, we should broadly expect a mere shift from one program to another-without any positive labor market response. It is only by enforcing the access conditions to these programs that the reform of the DI system can have an effect.

Finally, we explore a fourth set of simulations (simulation [4]) applying the policy change of simulation (1) on the basis of the estimates of specification (5) of table 4.2. Essentially, the idea is to see to which degree the inclusion or exclusion of age in the regression will influence the effect of reforms to the incentive structure. Given the significantly stronger estimates for the inclusive OV variable under specification (5) of table 4.2 (as compared to specification [4]), we unsurprisingly find a significantly stronger impact of the reform scenario in terms of the average remaining working life. Our results show that not controlling for age gives much lower work expectancy for the generous exit paths (CER, UI, and DI) and higher work expectancy for the OAP route-leading to an increase of more than 100 percent of remaining work years between the most generous and the least generous route. Simulation (5) thus provides a way of gauging the maximum effect that one can expect to obtain from a reform of eligibility of these programs. It shows that the reference simulations can be seen as conservative estimates of the likely real-world effects.

\subsection{Conclusion}

The present chapter set out to explore the link between health status, disability programs, and retirement in Belgium. We documented that disability trends in Belgium are largely disconnected from the employment and labor market participation of older workers ages fifty and older. In Belgium, it turns out that it is rather the CER and UI programs than DI that shape labor market behavior over time and across individuals.

While simple cross-tabulations of health and retirement probability tend to indicate a strong correlation, econometric analysis shows that such a relation does not uphold in a more complete estimation when controlling for a rich set of other variables. This finding is of quite some policy relevance, as it means that health is not a key driver of retirement in Belgium.

The regression analysis also shows that financial incentives as captured by 
the (inclusive) option value of retirement play a substantial role in explaining retirement behavior. Simulations based on these estimates document that by tightening the eligibility conditions for early retirement programs (CER, UI, and mostly DI), one can substantially increase the number of years an individual would stay active on the labor market. Our simulations also show that any tightening of such eligibility criteria in a given early retirement program would need to be associated with strict monitoring of access to the other early exit routes, as else the total effect would be marginal at best.

\section{Appendix}

Table 4A.1

The first principal component index for Belgium

Question

1st component

Difficulty walking $100 \mathrm{~m}$

0.286

Difficulty lifting/carrying weights over $5 \mathrm{~kg}$

0.296

Difficulty pushing/pulling large objects

0.306

Difficulty climbing stairs

0.281

Difficulty stooping/kneeling/crouching

0.283

Difficulty getting up from chair

0.261

Difficulty reaching/extending arms above shoulder

0.199

Difficulty sitting two hours

0.193

Difficulty picking up a small coin from a table

0.139

Body mass index

0.010

Limited activities

0.327

Self-reported health fair or poor

0.284

Number of nights stayed in hospital (last 12 months)

0.125

Number of weeks receiving professional nursing care (last 12 months)

0.180

Number of weeks stayed in a nursing home

0.038

Visit to a medical doctor (last 12 months)

0.237

Ever treated for depression

0.084

Doctor told you had stroke

0.110

Doctor told you had arthritis

0.197

Doctor told you had high blood pressure

0.078

Doctor told you had chronic lung disease

0.108

Doctor told you had diabetes

0.092

Doctor told you had cancer

0.067

Bothered by pain in back, knees, hips, or other joints

0.176 


\section{References}

BNB-Belgostat. 2013. Online Database on Economic Indicators for Belgium. http:// www.nbb.be/belgostat.

Dellis, A., R. Desmet, A. Jousten, and S. Perelman. 2004. "Micro-Modeling of Retirement in Belgium." In Social Security Programs and Retirement around the World: Micro-Estimation, edited by J. Gruber and D. Wise, 41-98. Chicago: University of Chicago Press.

Desmet, R., A. Jousten, S. Perelman, and P. Pestieau. 2007. "Microsimulation of Social Security Reforms in Belgium." In Social Security Programs and Retirement around the World: Fiscal Implications for Reform, edited by J. Gruber and D. Wise, 43-82. Chicago: University of Chicago Press.

Eurostat. European Labour Force Surveys 1983-2011. Luxembourg: Eurostat. http://ec.europa.eu/eurostat/en/web/microdata/european-union-labour-force -survey.

INAMI-RIZIV. 2013. "Statistiques des indemnités.” Brussels: INAMI-RIZIV.

Jousten, A., M. Lefebvre, and S. Perelman. 2012. "Disability in Belgium: There is More Than Meets the Eye." In Social Security Programs and Retirement around the World: Historical Trends in Mortality and Health, Employment, and Disability Insurance Participation and Reforms, edited by D. Wise, 251-76. Chicago: University of Chicago Press.

Jousten, A., M. Lefebvre, S. Perelman, and P. Pestieau. 2010. "The Effects of Early Retirement on Youth Unemployment: The Case of Belgium.” In Social Security Programs and Retirement around the World: The Relationship to Youth Employment, edited by J. Gruber and D. Wise, 47-76. Chicago: University of Chicago Press.

ONP-RVP. 2013. "Statistiques annuelles des bénéficiaires de prestations.” Brussels: ONP-RVP.

Pestieau, P., and J. P. Stijns. 1999. "Social Security and Retirement in Belgium." In Social Security and Retirement around the World, edited by J. Gruber and D. Wise, 37-71. Chicago: University of Chicago Press.

Poterba, J., S. Venti, and D. Wise. 2010. "The Asset Cost of Poor Health.” NBER Working Paper no. 16389, Cambridge, MA.

Stock, J., and D. Wise. 1990. "Pensions, the Option Value of Work, and Retirement." Econometrica 58 (5): 1151-80. 